\title{
Fibrose hepática medicamentosa: relato de caso
}

Luan Gavião Prado; Franciele de Cássia Siqueira Balbino, Larissa Cerqueira Barboza, Natália Gonçalves Santana Procópio, Igor Santos Freitas, Gabriel dos Anjos Celloto, Luiz Pedro Torres Costa, Mariana Cardoso da Costa Garcia, Lívia Miranda Popolízio, Lucas de Moura Sampaio, Caique Augusto Ribeiro Gomes

Centro Universitário de Itajubá, Itajubá, MG, Brasil

*Autor correspondente

e-mail: luangprado@hotmail.com

\section{Resumo}

O fígado é a maior glândula do corpo, sendo responsável por inúmeras funções: produção da bile, ácidos biliares, armazenamento de vitaminas e minerais, metabolização de medicamentos, síntese de fatores de coagulação, entre outros. Nos equinos, o fígado se localiza na parte medial do abdômen, dentro da abóbada diafragmática, e como os demais órgãos, pode ser acometido por afecções. A doença hepática é qualquer distúrbio capaz de causar lesão de hepatócitos, colestase ou ambas, como, por exemplo, intoxicações ou inflamações. Pode evoluir para uma insuficiência hepática, caracterizada pela incapacidade do fígado em remover do sangue as substâncias que comumente excreta e pela menor produção de substâncias, como a albumina, que é uma proteína plasmática ligada à cascata de coagulação. Nem sempre a doença hepática provoca insuficiência, uma vez que o fígado tem grande capacidade de reserva e regeneração, geralmente, é preciso que ocorra uma perda de 70 a $80 \%$ da massa hepática funcional para que se instale a insuficiência. Os sinais clínicos comumente encontrados são icterícia, encefalopatia hepática, edema, emaciação, diarreia, fotossensibilização, diátese hemorrágica e dor abdominal. Para realização de um diagnóstico fidedigno de uma doença ou insuficiência hepática, além dos sinais clínicos apresentados, faz-se necessária a realização de exames complementares como análises bioquímicas, exames de imagem e histopatológico. Entre os testes laboratoriais, incluem-se a determinação da atividade sérica de enzimas alanina aminotransferase (ALT), aspartato aminotransferase (AST), glutamato desidrogenase (GLDH) e ainda a mensuração da concentração sérica de substâncias que são normalmente produzidas ou removidas do sangue pelo fígado, como amônia e bilirrubina. 0 tratamento varia conforme a causa e tem como objetivo a retirada do motivo causador e suporte até a regeneração do órgão, mas uma vez perdida a função da massa hepática não há tratamento. 0 objetivo deste trabalho é relatar a ocorrência de fibrose hepática medicamentosa em um equino da raça Mangalarga Marchador. Foi atendido um equino, macho, não castrado, 5 anos, Mangalarga 
Marchador. Durante a anamnese, o proprietário relatou que estava administrando quatro tipos diferentes de anti-inflamatórios não esteroidais por aproximadamente dois meses, para tratamento de uma lesão de locomotor do animal. Ao exame físico inicial, o animal apresentava frequência cardíaca aumentada (68 b.p.m), frequência respiratória de 28 m.r.m, mucosas levemente ictéricas e sistema digestório com normomotilidade. Durante a inspeção, observou-se a presença de úlceras na parte interna dos lábios e, portanto, foram solicitados exames laboratoriais. No hemograma, o animal apresentou anemia arregenerativa normocítica normocrômica (Hemácias $5.83 \mathrm{milh} / \mathrm{mm}^{3}$ ), plaquetas $220.000 / \mathrm{mmc}$, hipoproteinemia (proteína total 4,8g/ dL, albumina 1,4g/dL), ureia 32,0 mg/dL, creatinina 1,08mg/dL, TGO (AST) 343,0 U/L, TGP (ALT) 21,0 U/L, fosfatase alcalina 290,0U/L. Devido às alterações encontradas no exame laboratorial e pela ausência de melhora clínica do animal, foi solicitada ultrassonografia de fígado, coração e pulmão. No transcorrer do procedimento, foi diagnosticado um quadro de hidropericárdio e hidrotórax; no fígado foi possível observar áreas de bordas irregulares e áreas de fibrose no parênquima hepático. Durante a internação, o animal começou a apresentar sinais de encefalopatia hepática como convulsões. Foi, então, indicada eutanásia do animal. À necropsia, pôde-se observar fibrose difusa do fígado, presença de líquido de aspecto translúcido em cavidade abdominal e torácica, além de aproximadamente $500 \mathrm{~mL}$ deste mesmo líquido no pericárdio. Conclui-se que a utilização de anti-inflamatórios não esteroidais acima da dose e do tempo recomendados pode levar à falência hepática, que teve como consequência o surgimento de hidroperitônio, hidropericário e hidrotórax devido à menor produção de albumina.

Palavras-chave: Equino. Fígado. Fibrose. 